\title{
HÁBITAT ABORIGEN EN SUELO URBANO: EL ÁREA DEL "GRAN TOBA"
}

KISZKA, María J. / ROCES, Carlos / ÁLVAREZ, Alejandro / AGUIRRE, Bruno

mariajosekiszka@hotmail.com / carlosroces55@hotmail.com / arqalvarezalejandro@gmail.com / bruno.aguirre.sae@gmail.com

Maestría en Gestión y Desarrollo de la Vivienda Social, Facultad de Arquitectura y Urbanismo, Universidad Nacional del Nordeste.

Palabras Clave: Hábitat aborigen; producción social del hábitat; suelo urbano. Keywords: Aboriginal habitat, social production of habitat, urban soil.

\section{RESUMEN}

Este trabajo problematiza la situación habitacional de un colectivo social que habita el denominado "Gran Barrio Toba". Constituye, desde nuestra perspectiva, un enclave en donde conviven comunidades aborígenes y criollos provenientes de migraciones de distintos períodos, y está conformado actualmente hasta por terceras generaciones de familias constituidas en el barrio. El área cuenta con equipamiento de una escuela, un centro de salud, al menos nueve iglesias evangélicas, y conviven allí organizaciones sociales y políticas, entre otras, cuyo máximo órgano de trabajo radica en la mesa de gestión indígena, en la que convergen un importante porcentaje y cuya representatividad en el área está en permanente disputa, lo que obstaculiza su legitimación.

\section{ABSTRACT}

This paper discusses the housing situation of a social group that inhabits the so-called Gran Barrio Toba. It constitutes, from our perspective, an enclave where there coexist aboriginal communities and creoles who arrived from migrations of different periods. Nowadays it consists even of third generations of families formed in the neighborhood. The area has a school, a health center, at least nine evangelical churches, and there coexist social and political organizations, among others. The maximum organ of work is the table of indigenous management where converge an important percentage of neighbors. Its representation in the area is in permanent dispute, which prevents his legitimization. 


\section{FUNDAMENTACIÓN}

El trabajo tiene como objetivo general problematizar las condiciones habitacionales del área del "Gran Toba", para la elaboración de un diagnóstico y posible intervención. Este colectivo social histórico que, a pesar de haber sido intervenido desde el Estado en varias oportunidades, se encuentra en agenda de gobierno para nuevamente operar con lo que anunciaron como un plan urbanístico, que implicaría la relocalización de familias y la construcción de viviendas nuevas. En este marco pretendemos tomar un caso de significación al que los aportes pudieran llegar a tiempo desde lo que entendemos tendría un "final anunciado" de impacto negativo para la comunidad.

Los integrantes del equipo se conformaron en torno a esta temática, para integrar en un caso trabajos previos con comunidades qom en un diagnóstico para la acción que pueda aportar a los modelos de gestión en extensión y transferencia con los que opera hoy la facultad de Arquitectura y Urbanismo de la UNNE, como parte de la actual gestión.

\section{MATERIALES Y MÉTODOS}

Se realizaron una observación directa, de la cual se obtuvo un relevamiento detallado del área e imágenes, y entrevistas abiertas en el área del Gran Barrio Toba durante los meses de mayo y junio del año 2014. Se recopiló información periodística, datos censales oficiales y se construyeron planos con la información actualizada. Las técnicas e instrumentos desarrollados para el análisis de lo recopilado son los propios de un abordaje multidimensional que implica un análisis particular de las partes que intervienen en la problemática y se influyen y complementan dialécticamente. Como antecedentes figuran aportes realizados desde distintas experiencias individuales, tanto de investigación básica como prácticas, a saber: AGUIRRE y ÁLVAREZ han participado como tesistas de grado en la experiencia Tierra Techo y Trabajo, en la que se abordó la problemática de comunidades originarias del interior de la provincia del Chaco proyectando y ejecutando prototipos de vivienda destinados a estas comunidades; KISZKA realizó observación directa y entrevistas a residentes de los barrios Mapic (20052006) y Chelillí (2010), y desde 2011 hasta la actualidad en el barrio Toba. Asimismo, se colaboró en experiencias participativas de diseño de viviendas con comunidades indígenas en las localidades de General San Martín y Pampa del Indio (2009), que oficiaron también de insumo para contrastar los datos primarios obtenidos. Por su parte, ROCES desarrolló la experiencia de diseño de un prototipo de un edificio escolar para una comunidad toba y actualmente realiza actividades vinculadas con la temática como docente investigador, en la Facultad de Arquitectura y Urbanismo de la UNNE.

\section{DESARROLLO DEL TRABAJO}

\section{Descripción}

"Corresponde al Congreso reconocer la preexistencia de los pueblos indígenas argentinos. Garantizar el respeto a su identidad y el derecho a una educación bilingüe e intercultural; reconocer la personería jurídica de sus comunidades y la posesión y propiedad comunitarias de las tierras que tradicionalmente ocupan y regular la entrega de otras aptas y suficientes para el desarrollo humano; ninguna de ellas será enajenable, transmisible ni susceptible de gravámenes o embargos. Asegurar su participación en la gestión referida a sus recursos naturales y a los demás intereses que los afecten. Las provincias pueden ejercer concurrentemente estas atribuciones". Artículo 75, inciso 17, de la Constitución Argentina.

En la ciudad de Resistencia, capital de la provincia del Chaco, en el año 1971, el Estado construyó un barrio 


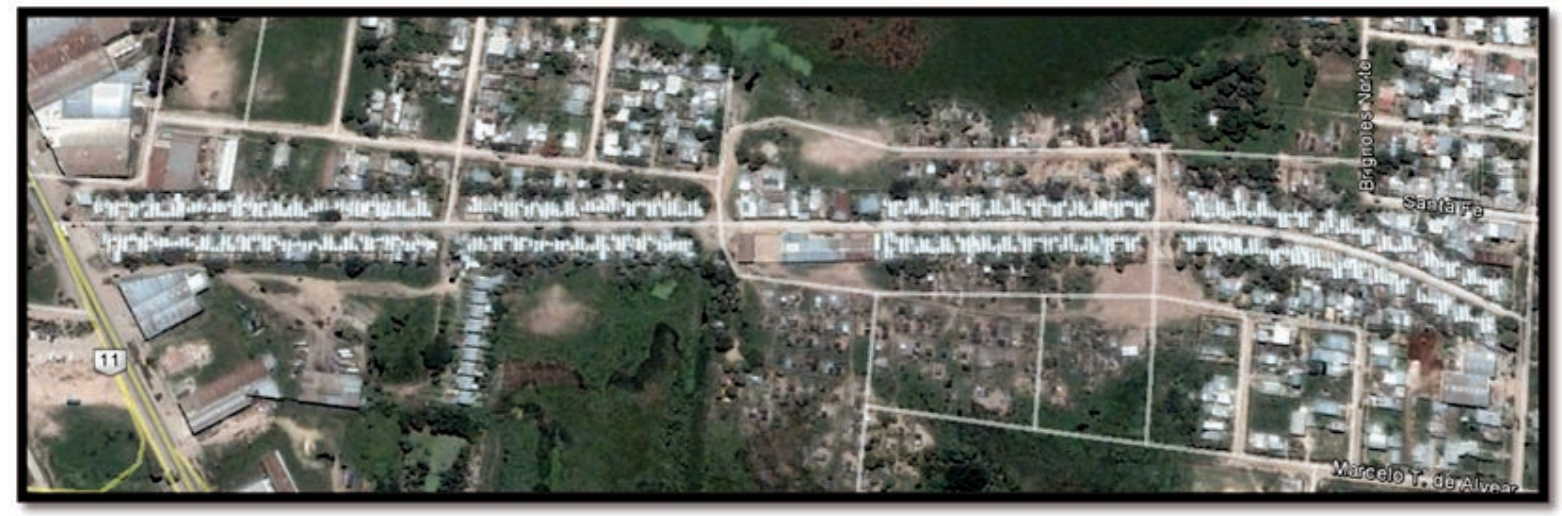

Imagen satelital de barrio Toba (viviendas agrupadas linealmente) y Área del Gran Barrio Toba. Año 2001

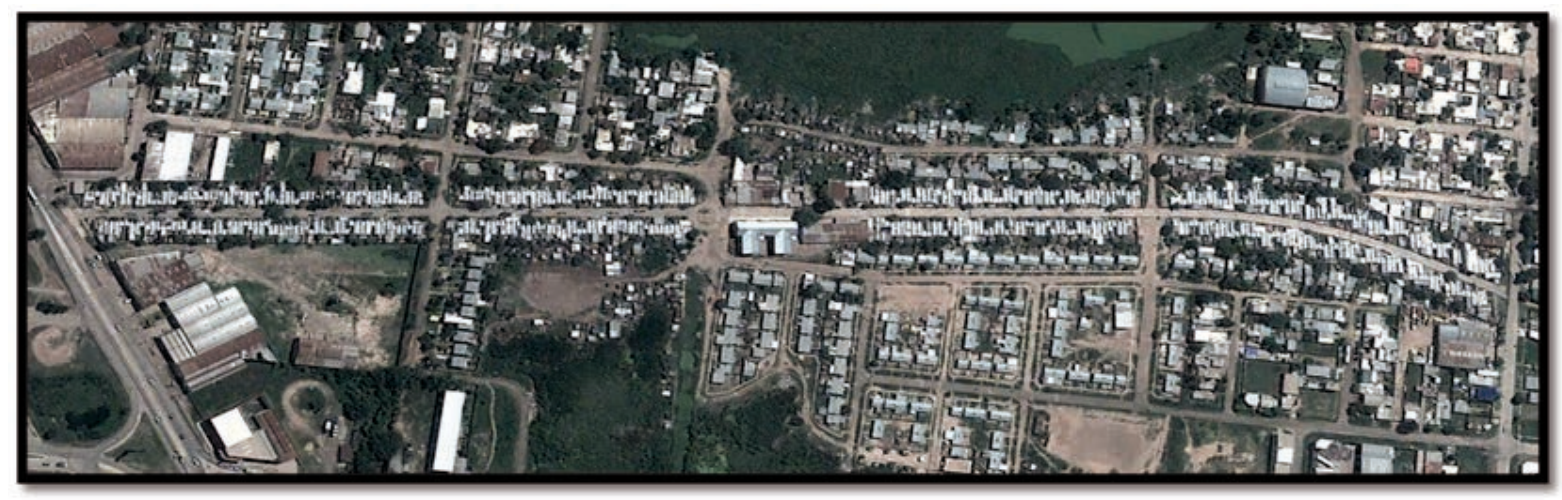

El barrio original fue construido con infraestructura de energía eléctrica y agua, pero los asentamientos posteriores, de ocupación irregular, carecieron inicialmente de estos servicios. Luego, con la regularización de la tenencia, se logró la construcción de las viviendas y la provisión de estas infraestructuras básicas.

de viviendas prototípicas económicas conocido como "barrio Toba", en un área tradicionalmente habitada por poblaciones de etnia toba o qom. A partir de ese momento, la comunidad fue creciendo y expandiéndose territorialmente hasta el día de hoy, conformando lo que se da en llamar el "Gran Barrio Toba", que incluye también nuevos asentamientos irregulares, con viviendas de carácter precario, con condiciones de vida insalubre y en terrenos inundables.

Ubicado en el sector norte de la ciudad, próximo a la Ruta Nacional N. ${ }^{\circ} 11$, el barrio Toba inicial se construyó sobre la antigua traza del Ferrocarril Santa Fe. Posteriormente, como consecuencia del crecimiento demográfico de la población originaria y de las constantes migraciones desde las áreas rurales, se generaron asentamientos espontáneos que se ubicaron en terrenos aledaños, bajos e inundables y deficientes en infraestructura y equipamiento. A estos asentamientos se los conoce como barrios Cacique Chelliyí, Cotap, El Rincón y Crescencio López. Algunos fueron consolidados mediante acciones del Estado, con la construcción de viviendas nuevas, y en otros se mantienen las condiciones de precariedad.

Su relación con la trama urbana es conflictiva, ya que el trazado urbano ejecutado no se condice con el trazado ortogonal imperante. En sus orígenes, su situación aislada de la trama urbana consolidada no impactó en el territorio, pero la continua expansión de ciudad llevó a la consolidación del sector, respetando la disposición ortogonal, que ante el contacto con el trazado lineal del barrio Toba significó una ruptura que aisló, aún más, al barrio, volcado en su traza original a una calle principal y con los fondos de las parcelas hacia los predios linderos. Los asentamientos posteriores, cuando regularizaron su situación, utilizaron el trazado tradicional de damero.

Este sector urbano, en general, dispone de equipamientos educativos y de salud y transporte público urbano, en todos los casos deficientes en sus prestaciones, y no presenta espacios adecuados para la recreación y el deporte. Toda actividad social se desarrolla en la calle peato-vehicular-plaza, por donde también deben desplazarse los vehículos de los vecinos, proveedores, maestros y toda otra persona que quiera acceder a las viviendas, comercios o servicios del barrio, y los escasos espacios libres lindantes.

La accesibilidad se da a través de la calle central, pavimentada y conectada a la Ruta Nacional N. ${ }^{\circ} 11$ y a otras calles secundarias que la articulan con el resto de la ciudad y el equipamiento disponible en el entorno. Estas calles son en algunos casos discontinuas y están en regular estado de mantenimiento, lo que 
provoca dificultades para el acceso de personas y vehículos.

La organización social del barrio, integrado por vecinos de ascendencia mayoritariamente qom, presenta formas orgánicas poco claras, en las que existe clientelismo político con intereses de varios partidos políticos en disputa por los espacios. Las prácticas políticas presentan en algunos períodos una fuerte participación partidaria; en época de campañas electorales, el accionar de los "punteros" políticos como referentes del barrio constituye la promesa de beneficios por parte de organismos del Estado y el reparto de artículos de primera necesidad mediante bolsones de mercadería. Al estar fuertemente divididos políticamente, esencialmente entre simpatizantes de las dos fuerzas políticas mayoritarias de la provincia (Radicalismo y Justicialismo) y otras minoritarias de base social, las diferencias y la disputa por los espacios políticos de los partidos dominantes agudizaron la brecha entre los distintos grupos, que imponen sus formas organizativas. En este contexto, el vecino común no cree en las organizaciones y sus referentes, y su participación se encuentra limitada.

La educación formal no es tomada por ellos como algo significativo, y existe un bajo nivel de escolarización. Esto también puede estar influido, si se quiere, por la dimensión económica, que refuerza la deserción. El aprendizaje se da de manera instrumental desde lo cotidiano y para la supervivencia, y tienen gran incidencia las habilidades técnicas que se adquieran para, entre otras cosas, la producción de artesanías.

Se ha institucionalizado en el barrio Toba la Escuela de Gestión Indígena, tanto en el nivel primario, secundario como terciario, y se entiende como una reivindicación de las comunidades en cuanto a lo identitario. La conservación de la lengua es vista como preservación de la cultura, pero es algo que lejos de resguardarse se va silenciando. Para evitar esto lograron que se sancionara la Ley N. ${ }^{\circ} 6691$ de la provincia del Chaco, que prevé la educación bilingüe en las escuelas con asistencia de hijos de pueblos tobas. A partir del ciclo lectivo 2011, las escuelas están obligadas a regirse por esta ley.

También existen instituciones religiosas, con nueve templos evangélicos y ninguna iglesia católica dentro del barrio. Estas instituciones generan actividades con gran número de participantes, especialmente en días festivos o ceremonias, aunque las acciones son inconexas y sin interacción entre ellas. A pesar de ello, la propuesta de la iglesia evangélica les permite expresar plenamente su júbilo; esto se puede observar en los festivales que organizan asiduamente, donde se visten de vivos colores, cantan y bailan. Podemos decir que esta manera de culto concibió rasgos de su cultura, brindándoles cobijo. El indígena encontró un verdadero refugio en lo religioso, más allá de una demanda espiritual. Es esta organización la que tomó la problemática de las reivindicaciones de estas comunidades y, respetando su esencia, supo contenerlos.

Las actividades recreativas se desarrollan grupalmente, y en este sentido, desde niños la identidad grupal se va reforzando. Las actividades recreativas colectivas se dan generalmente en el ámbito religioso los fines de semana, y los niños específicamente se concentran jugando al fútbol.

Un aspecto que se observa de manera negativa en las comunidades en la actualidad es que la desesperanza, la falta de integración, la discriminación que padecen principalmente los jóvenes los arroja a padecer adicciones, tanto al alcohol como a las drogas, y lamentablemente esto afecta también los modos de recreación de estos sujetos. En las calles del barrio, a determinada hora de la tarde, se registra habitualmente a muy alto volumen la emisión de música, generalmente de connotación religiosa.

El hábitus ${ }^{1}$ en el que se constituyen estos sujetos tiene en general un alto sentido de grupo; se identifi- 
"hablamos de un sujeto producido socialmente, atravesado por distintos condicionantes en contextos diversos: ser indígena invadido por comunidades criollas en un contexto rural o ser ocupante en suelo urbano."

can con los grupos y se constituyen como sujetos en ellos. El estudio de estos grupos, las instituciones y organizaciones que atraviesan a estos sujetos, que los forman y los conforman, nos permite caracterizar de manera más próxima la dimensión sociocultural.

Físicamente podemos observar: hacinamiento, falta de terrenos, equipamientos e infraestructuras deficitarias, vandalismo, lagunas sin mantenimiento, falta de espacio recreativo, entre los aspectos más destacados.

\section{MARCO TEÓRICO}

El desplazamiento y radicación de los tobas en las zonas periféricas de la ciudad de Resistencia, hacia la década de 1950, fue un hecho espontáneo relacionado con la crisis agrícola-forestal que azotó el interior del Chaco. La actividad taninera y la cosecha del algodón eran los pilares de la economía chaqueña, pero con la caída de los precios y la falta de demanda externa se iniciaron tiempos muy difíciles para los pueblos del interior y sus productores agrícolas. Los criollos y aborígenes colonos, jornaleros y obrajeros se movilizaron hacia las ciudades en busca de trabajo y mejores condiciones de vida, y provocaron en ellas un importante impacto demográfico y espacial (GUARINO, 2006). Se observan desplazamientos territoriales permanentes en la construcción histórica de los tobas: hablamos de un sujeto producido socialmente, atravesado por distintos condicionantes en contextos diversos: ser indígena invadido por comunidades criollas en un contexto rural o ser ocupante en suelo urbano. La

\footnotetext{
1 Por hábitus BOURDIEU entiende el conjunto de esquemas generativos a partir de los cuales los sujetos perciben el mundo y actúan en él. Estos esquemas generativos están socialmente estructurados: han sido conformados a lo largo de la historia de cada sujeto y suponen la interiorización de la estructura social, del campo concreto de relaciones sociales en el que el agente social se ha conformado como tal. Pero al mismo tiempo son estructurantes: son las estructuras a partir de las cuales se producen los pensamientos, percepciones y acciones del agente: "El hábitus se define como un sistema de disposiciones durables y transferibles -estructuras estructuradas predispuestas a funcionar como estructuras estructurantesque integran todas las experiencias pasadas, y funciona en cada momento como matriz estructurante de las percepciones, las apreciaciones y las acciones de los agentes cara a una coyuntura o acontecimiento y que él contribuye a producir" (BOURDIEU, 1972: 178).
}

búsqueda debe orientarse a reconstruir la cultura indígena en sentido amplio, en los diversos contextos. La etnia qom fue invadida por el criollo y los inmigrantes, despojada del derecho de uso de la tierra, expresando una contradicción entre naciones donde una oprime a otra a través de la negación de derechos. El desmonte desmedido generó un alto impacto negativo en el medio ambiente, que repercutió en la calidad de vida de los pueblos originarios. La política de producción agraria favoreció la gran expansión de los terratenientes sobre la base de la mercantilización de la tierra y de la renta. ${ }^{2}$ Ante esta adversidad fue que decidieron migrar, en búsqueda de mejores escenarios en los centros urbanos.

Es posible comprender la lógica de la apropiación territorial de estas comunidades a partir de entender su impronta sociocultural, construida desde su edificación histórica. Un itinerante camino, de búsqueda y persistencia, de adaptación activa, de resignaciones y también de ganancias. Si consideramos los actos y testimonios de las comunidades, podemos detectar que son sistemas abiertos, en los que no solo hay contacto, sino intercambio. Sus historias de vida remiten frecuentemente a hazañas de desplazamientos, de luchas y de resistencia, respecto de la disputa por el control de su presente y destino. Trasciende que los que permanecen en contexto rural tarde o temprano serán desterrados, "vendidos o regalados" dentro de las transacciones de tierras que administra el Estado provincial, y que por derecho les pertenecen. Atravesado por distintas situaciones, instituciones, organizaciones, el sujeto responde a una solicitud externa, impuesta por un sistema instituido en el cual las características estrategias de estas comunidades expresan su resistencia de manera instituyente.

\footnotetext{
2 En los fundamentos económicos de la "participación en plusvalías" JARAMILLO expresa: "Para tener acceso a la tierra, que aparece como una condición indispensable para su producción, el capitalista se ve obligado a pagar una suma de dinero por ello, debe arrendar la tierra. Esta suma, que en este caso más general y simplificado toma la forma de un pago periódico (el canon de alquiler, que se abona cada vez que tiene lugar un proceso productivo), es desde luego una parte del valor generado en la producción y que va a parar a manos del terrateniente".
} 
El término de frontera en este relato se hace presente como una imposición, algo que deben sortear, burlar, vencer, y no como algo natural. Es un dato la noción de tiempo, de imposición de un ritmo de cotidianidad. El toba, donde quiera que habite, sea el campo o la ciudad, lleva consigo una cultura milenaria, transmitida generacionalmente.

A partir de un análisis de las particularidades socioculturales, se realiza una resignificación tanto por cada individuo, como por la comunidad qom. Se parte de que a raíz de un cambio de contexto, rural en alternancia con urbano, y evaluando la situación actual de cada uno de estos, se deben reconstruir las concepciones que se manejan respecto de esta etnia. Hablamos de un sujeto producido socialmente, atravesado por distintos condicionantes en contextos diversos: ser indígena invadido por comunidades criollas en un contexto rural y a la vez ser ocupante en suelo urbano, desde donde es una necesidad plantearse una mirada del indígena como ser integral en distintos contextos. Por otra parte, es importante incorporar al debate que esta desterritorialización afecta no solo a los tobas, sino que además es un escenario de precariedad y pobreza compartido con los criollos.

En nuestro país, a partir de la reforma constitucional de 1994, se consagró el derecho de todos los habitantes de la nación a gozar de un ambiente sano y equilibrado. El artículo 41 de nuestra constitución reza: "Todos los habitantes gozan del derecho a un ambiente sano, equilibrado, apto para el desarrollo humano y para que las actividades productivas satisfagan las necesidades presentes sin comprometer las de las generaciones futuras y tienen el deber de preservarlo. El daño ambiental generará prioritariamente la obligación de recomponer, según lo establezca la ley. Las autoridades proveerán a la protección de este derecho, a la utilización racional de los recursos naturales, a la preservación del patrimonio natural y cultural y de la diversidad biológica y a la información y educación ambientales...". Desde aquí, el cuidado del ambiente implica respetar el derecho que le cabe a cada habitante, en tanto se respete también el de las generaciones futuras, siempre y cuando no se perjudiquen la salud o los recursos naturales. Culturalmente las comunidades se han caracterizado por desarrollar su cotidianidad en diálogo armónico con su entorno, pero tanto la segregación cultural como espacial a la que son sometidos los reconfiguran desde el descuido del entorno. El constante incremento de la densidad poblacional del área, sumado a la inacción del Estado ante esta situación, complica el estado de contaminación ambiental con basurales a cielo abierto, zanjones con desechos inorgánicos, alcantarillas con agua estanca, residuos sólidos y patológicos, como así también la incineración de residuos, deviniendo todo esto básicamente en la contaminación del suelo, el agua y el aire.

Se encuentra en proceso de concreción, en la ciudad de Resistencia, la premisa "educación bilingüe e intercultural", cuyos detalles se ampliarán seguidamente. La segunda premisa, "participación en la protección, preservación, recuperación de los recursos naturales y de los demás intereses que los afecten y en el desarrollo sustentable", no solo es omitida, sino también es violada permanentemente, fundamentalmente con el avance de la frontera agrícola y sus implicancias en los modos de habitar. Respecto del tercer inciso, que señala "elevación socio-económica con planes adecuados", el Estado no logra brindar la satisfacción de necesidades, en parte porque sus prácticas han desvirtuado en demasía las condiciones iniciales de hábitat y también porque no se lo propone. Se debe considerar con qué parámetros se realizan las acciones de asistencialismo desde el gobierno hacia las comunidades, y su directa relación con el uso y administración del territorio.

La descripción de las condiciones del hábitat desde una dimensión sociocultural obliga a reflexionar sobre las prácticas de la vida cotidiana de estos pobladores. El toba tiene la particularidad de respetar y preservar 
"A donde quiera que vayan cargan con años de costumbres, tradiciones, ritos y creencias desde los que se conforman."

sus costumbres, que fueron transmitidas de generación en generación. La cultura se transmite de este modo, pero este sujeto se re-significa permanentemente, y desarrolla actividades que le permitan la supervivencia desde el punto de vista de una adaptación activa y no desde la alienación. A donde quiera que vayan cargan con años de costumbres, tradiciones, ritos y creencias desde los que se conforman. De hecho, el Chaco está declarado como provincia bilingüe, donde la segunda lengua oficial es la toba.

En el aspecto político, el agrupamiento en movimientos sociales surge como una necesidad de reivindicación de este colectivo social. "La lucha", como denominan al ejercicio de protesta social, es básicamente la herramienta de gestión que adquieren estas comunidades. Ante un fracaso seguro que les ofrecen las políticas actuales de inequidad a estos individuos, a estas poblaciones, el hecho de manifestarse, "luchar", es una oportunidad de supervivencia ante una decepción anunciada. El mecanismo de plantear al Estado, a la sociedad, una necesidad reivindicativa se expresa en "piquetes" (interrupción del tránsito en rutas o calles) o "acampes" (agrupamiento organizado de individuos); en ambos actos, el fin que los convoca es la manifestación.

Para comprender la dinámica económica, GUARINO expone: "Los aborígenes sobreviven su pobreza con empleos temporarios resultantes de las changas, ladrillerías y venta de artesanías, o del asistencialismo político de los planes sociales. La condición de clase social excluida compromete la identidad étnica impidiendo reflexionar sobre la racionalidad y capacidad de organización social con la que asumen las tensiones y las resuelven" (GUARINO, 2006). En este análisis, es importante destacar que el factor económico conlleva una serie de implicancias a la hora de realizar nuestro estudio: la falta de trabajo formal de gran número de los habitantes de esta comunidad los condiciona a continuar con la producción de artesanías, así como a malvender su fuerza de trabajo. La escasa porción de suelo con la que cuentan en la ciudad les impide producir alimentos, aunque se observen contadas excepciones. Desde este punto de vista, es importante destacar que sus modos de producción están en armonía con el medio que los circunda. SHIVA plantea que "la dominación que se da en la sociedad patriarcal se sustenta en las relaciones socioeconómicas de la sociedad industrial que ha llevado a la crisis ecológica" (SHIVA, 1995). A esa problemática es necesario incorporar las consecuencias, ya citadas, de la concentración de tierras en pocas manos y la obligada migración a la que se someten las comunidades originarias del monte chaqueño. En este sentido, las mujeres son consideradas por SHIVA como "cuidadoras innatas del planeta y víctimas de la degradación ambiental, ocurrida debido a un modelo de desarrollo que atenta contra la naturaleza y la población femenina. Esta última, por ende, es concebida como agente de cambio y liberación, dada su 'perspectiva de sobrevivencia' o 'principio de feminidad', a partir de cuya actuación será posible restaurar una relación armoniosa entre ambiente $y$ sociedad". ${ }^{3}$

Respecto de la dimensión salud, actualmente existen debates en cuanto a si es correcto el uso de medicina tradicional o la asistencia al respecto del personal del centro de salud del barrio. Este último tipo de atención, si bien es históricamente resistido, presenta también un dato acerca de la evolución, en términos de transformación, que han tenido las enfermedades a las que son tendientes estos actores, en un escenario de precariedad ambiental. Un aspecto para problematizar desde esta dimensión es la repercusión de la contaminación ambiental. Los basurales a cielo abierto, el hacinamiento de las familias y el contacto permanente de las personas con un entorno degradado constituyen un foco de generación de problemas tanto respiratorios como en la piel. En este sentido, la medicina "natural" o "tradicional" alivia algunos síntomas que presentan estas evolucionadas afecciones, pero que tarde o temprano obliga a la comunidad a

3 ÉRIKA CARCAÑO VALENCIA. Ecofeminismo y ambientalismo feminista. Una reflexión crítica. 
demandar la asistencia sanitaria formal, en busca de medicamentos que calmen el dolor.

Se entiende por Ecosistema Urbano a un nexo de condiciones dinámicas entre los habitantes y sus actividades dentro de regiones o áreas urbanas. ${ }^{4}$ Para que un ecosistema urbano sea sustentable, deberá cumplir con los siguientes principios:

- Asegurar un adecuado abastecimiento de agua;

- Mantener la vegetación protegida;

- Preservar la calidad de los suelos;

- Asegurar condiciones sustentables para la fauna silvestre;

- Mantener el potencial de producción local de alimentos dentro del ecosistema y

- Crear un medio ambiente urbano que satisfaga las necesidades humanas.

Es claro que la salud del medio ambiente incide en la de los seres que lo habitan, y ahí reside la importancia de su abordaje. El discurso de preservación del medio ambiente, desarticulado de sus implicaciones en la vida cotidiana, cae en saco roto a la hora de la implementación de políticas tanto globales como locales. Las adversas condiciones de vida que atraviesan las comunidades de bajos recursos, asentadas en suelo urbano, promueven prácticas sociales que si bien son necesarias para la supervivencia ya que resuelven lo mediato, se tiene poca conciencia de sus efectos en la salud y el medio ambiente, según lo demuestran los observables.

EI IPDUV, por instrucciones del gobernador Jorge M. Capitanich, está elaborando un plan director para intervenir el área en cuestión, articulando acciones con distintos sectores de la comunidad, con otros organismos públicos y con la Municipalidad de ciudad de Resistencia. El plan pretende dar una respuesta integral a la crisis que presenta el barrio: hacinamiento (hasta treinta habitantes por vivienda),

4 Fuente: Módulo de Salud y Ambiente, del Posgrado de Médicos Comunitarios. viviendas precarias ubicadas en terrenos inundables (barrios Chelliyí, Crescencio López, El Rincón y Cotap), falta de infraestructuras (carece de red cloacal), equipamientos edilicios (mejorar las condiciones del edificio escolar, centro comunitario, registro civil, locales para la ejecución y venta de artesanías), equipamientos recreativos y deportivos, saneamiento de lagunas, recolección de residuos domiciliarios y la integración a la estructura urbana que permita la circulación del servicio público de transporte de pasajeros e insumos.

La complejidad del problema abordado puede ser considerada por los siguientes aspectos:

- Alta conflictividad social, producto de drogadicción, alcoholismo y falta de oportunidades laborales.

- Fragmentación social, dada por una comunidad dividida en cuatro grupos perfectamente identificados, con escasa interacción entre ellos. De hecho, el uso de los espacios es absolutamente diferenciado, y esta fragmentación abona la conflictividad social.

- La multiplicidad de referentes reconocidos por la comunidad: caciques, pastores evangélicos y punteros políticos, entre otros, que dificulta la identificación de interlocutores válidos.

- La crisis de la comunidad educativa de la escuela del barrio, producto de la división entre los nuevos integrantes y los antiguos docentes, que provoca un alto índice de días sin actividades académicas.

- La ocupación ilegal de los terrenos donde se asientan las viviendas y la falta de suelo urbano apto disponible para la construcción de nuevas viviendas y equipamientos.

- Las restricciones legales para la ocupación de los bordes de lagunas.

- La contaminación ambiental, producto de la falta de limpieza de lagunas, la existencia de basurales a cielo abierto, la falta de recolección de residuos domiciliarios, el reciclado de la basura por parte de integrantes de la comunidad, como medio de sustento económico, y la cultura de acumulación de estos, arraigada en los habitantes. 
"La expropiación de las tierras que habitaban, el cierre de fábricas en las que se empleaban fueron procesos todos teñidos de violencia e imposición."

Ante dicha complejidad, el IPDUV desarrolla una metodología multiactoral a efectos de tratar cada tema en particular e interrelacionarlos para obtener un resultado integral. Establece un enfoque interdisciplinario y transdisciplinario, que le permita resolver técnicamente cada tema por separado y en su conjunto, para alcanzar una respuesta que contemple soluciones integrales, como en el caso de la problemática ambiental, que requiere soluciones de saneamientos de lagunas, infraestructura de cloacas y optimización del sistema de recolección de residuos, con participación de organismos municipales y provinciales y los profesionales de la ingeniería, la agrimensura y la arquitectura. En este escenario de múltiples problemas, se están desarrollando acciones direccionadas sobre tres ejes principales: el eje social, el eje ambiental/lacustre y el eje étnico.

\section{DIAGNÓSTICO}

El concepto de territorio de los toba desconoce las fronteras que le plantean los límites de las ciudades, sean geográficas o políticas: las rutas, los alambrados, y se reconoce como parte de una cultura milenaria, sea que vivan en contexto rural o en la periferia de centros urbanos. Su territorio viene a ser aquel espacio físico que le brinda condiciones para la preservación de la vida: sea que vivan de lo que producen para el consumo, de planes de asistencia social que les brinda el Estado o de las artesanías que elaboran. Este contexto tan diverso (campo-ciudad) produce sujetos que se identifican con alguno o con ambos a la vez. Hay casos en los que para obtener un plan asistencial del Estado precisan residir en un asentamiento o barrio de la periferia, en donde levantan una casilla, y un integrante del grupo familiar se encarga de conseguir el cometido, aunque su elección de vida se encuentra en el campo. Las fronteras impuestas por el blanco no fueron convalidadas por estos indígenas. Desde lo identitario, ser un toba no está sujeto al medio en donde se habita: en el Impenetrable, en Resistencia o en Rosario. Trasciende que los traslados han sido una constante en estas comunidades (TAMAGNO, 2001-2007).
La problemática del territorio indígena en suelo urbano y su repercusión en el hábitat tiene origen en otro contexto. En distintos procesos migratorios debieron abandonar el contexto rural, en nuestro caso el monte chaqueño, para habitar los márgenes de las crecientes ciudades como Resistencia, Rosario o la Ciudad Autónoma de Buenos Aires. A kilómetros de donde residen actualmente, algunas décadas atrás, distintos procesos expulsaron a estas poblaciones de su tierra de origen, el monte de chaqueño. ${ }^{5}$ La expropiación de las tierras que habitaban, el cierre de fábricas en las que se empleaban fueron procesos todos teñidos de violencia e imposición. La crudeza de las acciones de expulsión no cesó en los procesos migratorios, y menos aún en los de asentamiento en las ciudades. El asentamiento en los márgenes implica en términos de ciudad condicionantes como hacinamiento, precariedad, aislamiento, inaccesibilidad, por citar las problemáticas más latentes.

El reagrupamiento de estos sujetos es un dato que comunica la capacidad de resistencia, demostrada históricamente. Tanto en el campo como en la ciudad, buscan congregarse como materialización de su identidad. Desde aquí la necesidad de revisar la visión que han tenido en la historia no solo distintos investigadores, sino también los informes periodísticos y otras fuentes, en función de lo que los testimonios de los toba narran respecto de las vivencias de la comunidad.

La información de base recopilada permite caracterizar el proceso de conformación del tejido urbanosocial en distintos etapas o fases que conviven según diferentes factores. En el área de estudio se pueden observar al menos tres situaciones diferenciadas a partir de las características del espacio (ver cuadro 1). Coexisten al menos tres fases de apropiación espacial:

5 El monte chaqueño, que se ubica al nordeste de la Argentina, contaba con recursos como el quebracho colorado y la plantación de algodón, pero las políticas monopólicas y las prácticas neoliberalistas llevaron a la inadecuada implementación de la siembra de soja en busca de una productividad económica, cara al equilibrio medioambiental. 
FASE VERNÁCULA: Ocupación del suelo, en una lógica desarrollada según la cual familias del interior de la provincia del Chaco, por falta de recursos que permitan la supervivencia digna, migraron, en distintos períodos ${ }^{6}$ a los centros urbanos, o bien familias excedentes que adquirieron una escasa porción de suelo en la periferia de la ciudad, que generalmente no cuenta con la infraestructura y equipamiento necesarios. Allí realizan una instalación precaria que los abriga del medio físico. Gestionan recursos, tanto económicos como habitacionales, a través de distintas organizaciones de carácter político o religioso, en las cuales toma fuerza lo colectivo, que caracteriza la organización. La respuesta del Estado llega por lo general de manera desarticulada, con precarios trabajos previos de orden técnico y una escasa supervisión a las empresas que ejecutan con suficiente libertad de interpretación las empobrecidas propuestas habitacionales.

En las últimas décadas se están desarrollando procesos de ocupación de tierra y materialización de viviendas, de nuevas familias, de pobladores urbanos de segunda y tercera generación, que no padecieron la problemática del éxodo rural, pero que con similares mecanismos se apropian en la ciudad de terreno vacante, en las proximidades de los pretéritos barrios, profundizando la segmentación y desintegración de estas áreas.

FASE DE INTERVENCIÓN: Las diversas intervenciones del Estado han operado con soluciones poco adaptadas a las costumbres, y si bien mejoran las condiciones de salubridad y confort en algunos aspectos, la falta de lectura de la dimensión sociocultural genera un rápido deterioro.

FASE DE REAPROPIACIÓN: En el proceso de reapropiación, la dimensión económica opera de manera tal

6 A partir de los años 60 diversas crisis de producción, como de algodón, caña de azúcar y explotación forestal, de incidencia en el ámbito rural obligaron a los pobladores a migrar a los centros urbanos en busca de mejores condiciones de vida. que no les permite la mayoría de las veces producir una mejora o sostener el artefacto vivienda en condiciones adecuadas de confort. Un ejemplo explícito es que a partir de la entrega de viviendas, el perímetro del barrio Chelliyí fue cerrado con pallets, recolectados con la práctica del cirujeo. De la caracterización del proceso, se desprende un primer análisis comparativo entre las respuestas particulares que obtienen las familias de manera individual, la respuesta colectiva e impersonal que da el Estado y las adaptaciones que debe realizar cada familia para mejorar las prácticas de las políticas públicas en materia de vivienda, que en ocasiones tienden a mejorar ciertas condiciones y en otras generan conflictos que resolver.

Hablar de una comunidad indígena en suelo urbano es hablar de sujetos resignificados por un contexto. Desde una perspectiva multidimensional, analizar la problemática del hábitat indígena en suelo urbano, desde lo sociocultural, implica atender la cuestión de la vida cotidiana, analizando los hábitos y costumbres observables de estos sujetos. Esta mirada se referirá en particular a la caracterización de este cotidiano que los constituye como sujetos, desde distintas dimensiones que los atraviesan y los conforman. ${ }^{7}$

Este espíritu de comunidad se ve fortalecido principalmente por dos instituciones que los atraviesan como sujetos: la política y la religiosa. La falta de una organización que unifique todas las vertientes políticas en una propuesta en beneficio de las mayorías favorece a los partidos políticos que solo buscan de esta manera una representatividad para las elecciones. Eso queda muy claro en las inversiones que hace el Estado para resolver el "problema" habitacional con propuestas que tienen de trasfondo un enfoque economicista y de una sola dimensión, que terminan favoreciendo a las empresas constructoras y a intereses económicos

7 Este planteo se basa en lo postulado por ENRIQUE PICHÓN RIVIERE, quien entiende al sujeto atravesa do por una compleja trama vincular que lo constituye como tal. Al respecto son considerados también los aportes realizados por MICHEL FOUCAULT, en cuanto a la configuración del sujeto a través de Instituciones, lo desarrollado por PIERRE BOURDIEU en relación con el concepto de hábitus, y la multidimensionalidad en el paradigma de la complejidad, abordado por EDGAR MORÍN. 
"...las viviendas que brinda el Estado, sin un acompañamiento de políticas más integrales que aborden la problemática de la segregación y la pobreza de manera estructural, reforzarían los fenómenos que con ella se aspira a amortiguar."

que están por encima de las necesidades. Este cambio de contexto, si bien ofrece un escenario diferente, dista muchas veces de mejorar las condiciones que se aspiran alcanzar, en la búsqueda de un mejor pasar: el hacinamiento en las reducidas viviendas, la falta de infraestructura, la falta de tratamiento y la desarticulada recolección de residuos son algunas de las adversidades que tornan al hábitat urbano un medio insalubre y precario para el desarrollo de la vida de estas y otras comunidades.

\section{PROYECCIÓN}

RASGOS RECESIVOS. La inminente construcción de viviendas aportaría a mejorar la calidad de vida en la comunidad del área del Gran Barrio Toba, especialmente en las condiciones de cobijo e higiene. Sin embargo, las viviendas que brinda el Estado, sin un acompañamiento de políticas más integrales que aborden la problemática de la segregación y la pobreza de manera estructural, reforzarían los fenómenos que con ella se aspira a amortiguar. Al respecto, algunos testimonios de vecinos manifiestan los obstáculos de mantener la vivienda que se les asigna por no poder pagar los impuestos, realizar mejoras o el mantenimiento cotidiano que genera el uso, entre otros.

RASGOS EMERGENTES. La implementación de políticas públicas de vivienda sigue tendiendo al abordaje y resolución de las problemáticas del hábitat desde la perspectiva de construcción. Una visión desde la integralidad permitiría debilitar la rápida degradación de las acciones por parte del Estado, en las últimas intervenciones realizadas en escuela y centro de salud, por ejemplo.

RASGOS DOMINANTES. Es posible registrar hábitos que perjudican el entorno, y este entorno en degradación perjudica la salud de la comunidad. Es decir, hay una interacción dialéctica entre los actores medio social-medio físico. Este fenómeno sería posible de controlar, modificando estos hábitos. Otro aspecto para destacar es que los hábitos se dan tanto en la escala comunitaria como en la domiciliaria. El conocimiento ecológico local, problematizado, asumido y elaborado comprometidamente con la comunidad indígena que habita el suelo urbano, contribuiría al desarrollo más sostenible de la vida cotidiana. Esto repercutiría directamente en el bienestar humano, en particular en la salud (etnoecología). ${ }^{8}$ En este sentido, se considera necesario el abordaje multidimensional de la problemática del medioambiente. Estas reflexiones son transferibles a las condiciones de vida de la comunidad criolla, con la que comparten iguales condiciones de segregación y marginación.

El abordaje multidimensional nos permitirá deconstruir el problema desde la policausalidad, y permitirá un abordaje más integral de la compleja problemática. Si bien este trabajo se desarrolla desde un marco teórico limitado, los aportes testimoniales de vecinos de la comunidad enriquecen y mejorarán este análisis.

\section{OBJETIVOS}

\section{Objetivo General}

"Incidir en el actual proceso de transformación del área del Gran Barrio Toba". Estas acciones están destinadas a articular e integrar la comunidad al proceso de transformación de alto impacto social que sucede en el Gran Barrio Toba, producto de las diversas políticas estatales, generando espacios de participación comunitaria. Las intervenciones serán disparadas en

\footnotetext{
8 La etnoecología ha pasado de focalizarse en el estudio de los sistemas indígenas de clasificación al estudio del conocimiento ecológico local, entendido como una forma compleja de adaptación y modificación del hábitat, fruto del proceso de coevolución entre cultura y naturaleza (BERKES ET ÁL., 2000). Mientras que la investigación inicial en etnoecología habría ayudado a valorar los sistemas locales de conocimiento ecológico como sistemas lógicos y complejos, la investigación actual subrayaría su potencial en la mejora del bienestar de la sociedad actual. Por ello, a nuestro parecer, la etnoecología actual no presenta una ruptura conceptual con la etnoecología de los años 50, aunque el nuevo enfoque también incluye aportaciones de otras ramas de la antropología ecológica, como la antropología ecológico-energética de RAPPAPORT, que antecede estudios de autores Como FIKRET BERKES, VíCTOR TOLEDO y CARL FOLKE (REYES GARCÍA V., MARTÍ SANZ, N., 2007).
} 
función de las necesidades reales y las acciones efectuadas hasta el momento (así como también las futuras), que afectan el área Gran Barrio Toba, y las que serán propuestas, elaboradas y ejecutadas para modificar las condiciones en las que se encuentra la comunidad. Dentro del objetivo central de este trabajo, se profundizarán cuatro objetivos particulares que apuntan a distintos aspectos de problemáticas específicas.

\section{Objetivos particulares}

- Generar espacios de trabajo entre los diferentes actores.

- Aportar al desarrollo urbano y ambiental del área.

- Fortalecer la integración comunitaria, principalmente de la población joven.

\section{PLANIFICACIÓN DE LA ESTRATEGIA DE ABORDAJE}

Nuestra estrategia de abordaje consiste en generar una mesa de trabajo dinámica, abierta, participativa y autogestora, partiendo de un diagnóstico previo del caso (fase 0 ).

- Fase 1. Los técnicos se constituirán en equipo de trabajo para reelaborar el diagnóstico en conjunto con la comunidad y con agentes de las diversas instituciones.

- Fase 2. A partir de entonces, el trabajo conjunto evaluará y proyectará las posibles respuestas en función del diagnóstico, para la promoción del hábitat digno de diversa índole en la comunidad y toda el área.

- Fase 3. Una vez elaboradas las propuestas o proyectos, se ejecutarán las acciones previamente programadas entre todas las áreas de funcionamiento y actores participantes.
- Fase 4. Cada resultado de esas acciones, previsto o no, arrojará nueva información del caso que deberá evaluarse y reconsiderarse con todos los actores de la comunidad.

Para cerrar el ciclo (que comprende las cuatro fases), se plantean nuevos objetivos, desde metas a corto plazo y objetivos realizables, que promuevan el fortalecimiento comunitario, y estimulen la construcción de tejido social para la construcción de tejido urbano. (Vuelta a fase 0). Los actores reconocidos desde esta intervención propuesta son tres:

- Técnico: actores sociales que se vinculan con la comunidad a partir de una necesidad de transferencia y aprendizaje contextuado.

- Agente social: actores sociales que se encuentran insertos en la comunidad, cumpliendo diversos roles en instituciones que operan en el radio. Principalmente su misión es coordinar acciones con la mesa de gestión para que la institución a la que representan trabaje de manera coordinada.

- Vecino de la comunidad: actores sociales que se encuentran habitando el área de intervención. Interactúan con la comunidad y desde allí construyen con el otro sus realidades.

La caracterización acerca del rol del Estado respecto del trabajo en el área del Gran Barrio Toba estará en función del tipo de sociedad en la que está inmerso, el contexto político actual y los procesos de transformación social en la región y el país, y las prácticas detectadas en función de todo eso. Dentro del sistema democrático capitalista de gobierno, en el cual nos contextualizamos, no consideramos al Estado y todas sus dependencias -independientemente de la orientación política que las dirija- como un actor dentro de la estrategia planteada, sino más bien como un recurso. Es el actor comunitario quien buscará, trabajando integradamente con técnicos y agentes sociales, utilizar al recurso Estado para satisfacer las necesidades y resolver sus problemas. Esta acción actualmente se contrapone a la de los actores que 
dirigen las distintas dependencias del Estado, que utilizan este recurso para sus propios fines e intereses. Operativamente, los técnicos buscarían constituir diversas comisiones de trabajo con agentes sociales y vecinos, tomando tareas según diversos roles.

\section{CONCLUSIONES}

Habiendo reelaborado las distintas etapas metodológicas propuestas por el equipo docente en el proceso de realización del trabajo, y dejando expresadas las distintas posturas teóricas, se completó hasta el momento nuestro posicionamiento, y se delinearon estrategias para concretar nuestra propuesta.

A partir de los obstáculos y caminos recorridos, hemos decidido jerarquizar la figura y el rol que desempeñan los vecinos, los agentes sociales y los técnicos que desde la universidad aspiramos a transformar la realidad desde esta institución como un trabajo contextuado de aprendizaje, en sentido dialéctico y dialógico, de común unión entre técnicos y la comunidad. El rol del Estado es entendido desde una visión que los admite y reconoce en términos de recursos, y en esos términos cada vez que sea necesario. Desde esta visión con sentido de desarrollo local se plantea tomar contacto con ellos.

En todo presente se replica la historia, y en toda historia hay un presente. La situación actual de los ciudadanos de la etnia toba es un proceso abierto y dinámico, como el de cualquier comunidad. Los discursos y prácticas que pretenden delimitar fronteras, tanto culturales, sociales o territoriales, son los mismos que se benefician con sus padecimientos. 


\section{BIBLIOGRAFÍA}

BARRETO, Miguel (2008). "Un marco epistémico posible para la formulación de una política integral del hábitat para los afectados por situaciones de pobreza crítica en el AMGR" [CD]. En: Encuentro de Geohistoria Regional (XXVIII, 2008, Resistencia, Argentina). Conicet, 2008 (c). ISBN 978-987-21984-5-9.

BARRETO, Miguel (2010). "El Hábitat Digno como meta de una política integral de áreas urbanas deficitarias críticas, para la integración social desde los derechos humanos". En: Revista INVI N. ${ }^{\circ} 69$. Volumen 25, pp. 161-187. Edición: Instituto de la Vivienda, Facultad de Arquitectura y Urbanismo, Universidad de Chile, Santiago ISSN 0718-1299. Agosto de 2010.

BARRETO Miguel y BENÍTEZ, María Andrea (2009). "Lineamientos en la dimensión sociocultural para una política habitacional integral orientada a situaciones de pobreza crítica del AMGR". Actas XXVIII Encuentro de Geohistoria Regional. Instituto de Investigaciones Geohistóricas IGHI-Conicet.

BENÍTEZ, María Andrea (2006). "Desigualdad, conflictos sociales y segregación socio espacial. El caso de los asentamientos y urbanizaciones en la ciudad de Resistencia Chaco". Revista de estudios regionales y mercado de trabajo N. ${ }^{\circ}$ 2. Dic. de 2006. Editada por SIMEL- CEUR.

BENÍTEZ, Andrea (2000). "De la villa al barrio. Hipótesis sobre la construcción de la identidad de los ocupantes de tierra urbana en Resistencia, Chaco" [CD]. En: IV Congreso Argentino de Antropología Social. Colegio de Graduados de Antropología y la Facultad de Ciencias Sociales de la Universidad Nacional de Mar del Plata. 2000. ISBN: 978-9136-96-9.

GARCíA, Rolando (1986). "Conceptos básicos para el análisis de sistemas complejos". En: Problemas del conocimiento y la perspectiva ambiental del desarrollo. Coordinado por E. Leff. Siglo XXI Ed., México.

GARCíA, Rolando (1991). "La Investigación Interdisciplinaria de Sistemas Complejos". En: Serie Materiales 1/91. Centro de Estudios Avanzados. UBA. México-Buenos Aires.

GARCíA, Rolando (2000) El conocimiento en construcción. De las formulaciones de Jean Piaget a las teorías de sistemas complejos. Gedisa, Barcelona.

GUARINO, Graciela (2006). "Los tobas en la ciudad de Resistencia: El desafío de vivir en los márgenes". En: Cuaderno Urbano N 5 ISSN: 1666-6186, Junio 2006.

MINER, Horacio. Consejo de ritual entre el Nacirema. Universidad de Michigan. Antropólogo Americano, 58 (3) 503-507.

MILTON, Kay. Ecologías: antropología, cultura y entorno. Revista internacional de Ciencias Sociales, 154, 86-115

MORIN, Edgar (1995) Introducción al pensamiento complejo, Gedisa, Barcelona.

PICHÓN-RIVIERE, Enrique (1985) Teoría del vínculo. Buenos Aires. Nueva visión

PICHÓN-RIVIERE, Enrique y PAMPLIEGA DE QUIROGA, Ana (1985) Psicología de la vida cotidiana. Buenos Aires.

TAMAGNO, Liliana E. (2001) Tobas en la casa del hombre blanco. Ediciones Al Margen. ISBN: 9879248732.

SHIVA, Vandana (1995) Abrazar la vida. Mujer, ecología y desarrollo.

Madrid: Horas y Horas. [StayingAlive. Women ecology and survival. 1988] pp. 19-75.

ORTNER, S. (1979). ¿ Es la mujer con respecto al hombre lo que la naturaleza con respecto a la cultura? Antropología y feminismo. Barcelona. Anagrama, 109-132

REYES -GARCÍA V., MARTí SANZ N. (2007). "Etnoecología: punto de encuentro entre naturaleza y cultura". Ecosistemas. 2007/3. (URL: http://www.revistaecosistemas.net)

WILDE, Guillermo (2009) Religión y Poder en las Misiones Guaraníes. 